\title{
“NETWORK DESIGN” A MULTIDISCIPLINARY PROJECT TO RAISE AWARENESS OF THE INDISCRIMINATE USE OF PLASTICS
}

\author{
Silvia Nuere', Adela Acitores Suz', Laura de Miguel², \\ Esperanza Macarena Ruiz Gómez³, Eugenio Bargueño3, \\ Brezo Alcoceba ${ }^{4}$, Manuel Carmona ${ }^{1}$ \\ ${ }^{1}$ Universidad Politécnica de Madrid (Spain) \\ ${ }^{2}$ Universidad Internacional de la Rioja (Spain) \\ ${ }^{3}$ Universidad Complutense de Madrid (Spain) \\ ${ }^{4}$ Universidad Rey Juan Carlos and IADE Design School (Spain)
}

\begin{abstract}
The University is a meeting place for the transmission of knowledge, but the fact of being able to transmit values that complement student's training is beyond the exchange of information.

Through the call for educational innovation projects, we have the possibility of carrying out actions aimed at solving specific problems by applying innovative methodologies. In 2019, at the High Technical School of Engineering and Industrial Design (ETSIDI) from the Universidad Politécnica de Madrid (UPM), a project was awarded in collaboration with the High Technical School of Architecture (ETSAM-UPM), the IADE School of Design, the Universidad Rey Juan Carlos (URJC), the Universidad Internacional de la Rioja (UNIR), as well as the Faculty of Fine Arts of the Universidad Complutense de Madrid (UCM).

The project, called Network Design, is framed in the Science, Technology, Engineering, Arts and Mathematics (STEAM) environment, applying active approach methods to the problem of the indiscriminate use of plastics. We must promote in the students' skills they will need later in their professional life. Considering that students of different degrees are used to working with problem learning methodology, we think that an approach should be given that goes beyond obtaining a tangible product.

The proposal presented is based on the reuse of food container nets as an essential material to create an object, being a design product, a drawing, or a painting. The "Network" union with other universities encourages the work to be truly multidisciplinary and interuniversity, and that each participant collaborates to spread the project more widely by combining the different ways of tackling the same problem. It will seek to create harmony between the point of view of the materials' specialist, the landscape painter, the set designer, the fashion designer, the industrial and product designer, and the interior designer. We look for different creation approaches with a common purpose that revalues each plastic. The motto is making beauty from the uselessness and one of the most important objective
\end{abstract}


is encouraging awareness about the indiscriminate use of plastics through a design or an artistic approach.

Keywords: artistic collage, creativity, network design, plastic nets, product design, STEAM approach, sustainability, visual communication.

\section{Introduction}

In 2016, the waste generated annually in the European Community was close to 2,500 million tons (Mascareñas, n/g). Faced with this reality, the community authorities set new binding targets to manage recycling, among other elements, packaging waste more efficiently as a first step. They promote a circular economy as a production and consumption model that involves sharing, renting, reusing, repairing, renewing, and recycling products to increase their life cycle. In addition, the residual materials with which they are made are reused or recycled to generate new products (European Comission, 2020).

According to Ola Persson the intellectual roots of "circular economy" stems from K. E. Boulding in 1966 where people must find their place in the earth without unlimited resources in a cyclical ecological system. The specific term was coined in 1980 by David Pearce and R. Kerry Turner to explain a system between the interrelationships of the economy and the environment (Persson, 2015).

Design can be the useful tool to access a new economic activity thinking of the way of generating growth placing the accent on the benefits for the whole society. The European Community intends to extend the useful life of the products and consequently to reduce waste significantly, thus creating added value.

The application of the 6R philosophy - rethink, restructure, reduce, reuse, recycle and redistribute -, proposed by Greenpeace, appears as a proposal for consumer habits (Mascareñas, $\mathrm{s} / \mathrm{f}$ ).

According to 2019 annual report (Plastics Europe, 2019), in the world, the annual production of plastics in 2018 reached 360 million of tones, and in Europe, the production was 62 million of tones. One of the commitments of Europe, through the Voluntary Compromise 'Plastic 2030' is trying to avoid plastics ending in the environment. The intention is to augment the reutilization and recycling of all plastic packaging waste and contribute to a better efficiency of the resources. According to Greenpeace (Greenpeace, s. f.), in 2018 more than two thirds of the plastic consumption is concentrated only in six countries: Germany (24.6\%), Italy (13.9\%), France (9.4\%), Spain (7.6\%), United Kingdom (7.3\%), and Poland (6.8\%). Spain is the fourth country in the European Union with the highest demand for plastics, 
where up to $50 \%$ of them ended up in landfills in 2016. Most plastics are used in the manufacture of packaging, that is, in single-use products.

Marine litter is a global challenge, and it is unacceptable for waste, including plastics, to end up in the environment, rivers, or oceans up to 8 million tons every year according to the International Union for Conservation of Nature, making up $80 \%$ of all marine debris from surface water to deepsea sediments (International Union for Conservation of Nature, May, 2018). Plastics are valuable resources that bring numerous benefits to society by offering sustainable solutions in countless sectors. It is unfortunate that plastics, whether due to irresponsible behavior or poor waste management, end up abandoned in the environment (Plastics Europe, 2019).

"Plastic" seems to be a single material, but it is not. In the same way that we know there are different types of metals with different properties, plastics also form an extensive family of different characteristics. Each plastic is designed with specific properties that make it ideal for the application for which it is intended. This makes possible to provide highly efficient solutions in the use of resources. Plastic materials can be obtained from different sources, as fossil origin (oil, gas, etc.). They can come from renewable materials (cane sugar, starch, vegetable oils, etc.) or even from minerals (salt). Regardless of the nature of their raw materials, some plastics are also biodegradable. If they are properly collected and treated together with organic waste, they can biodegrade and become compost (Plastics Europe, 2019).

Once the plastics are made, they are asked for different uses, and packaging sums 39.9\%, far from construction and building that means $19.8 \%$, and following by automobile sector with 9.9\%. Packaging represents the biggest number of plastic uses.

The lifespan of plastics for packaging is less than a year, but can last for years and years, 15 or 50 years. From the plastic residues, there is a percentage that is thrown to the landfill (24.9\%). A $42.6 \%$ is energetically recovered, and only $32.5 \%$ is recycled.

Every year the UPM makes a call for innovative learning projects to propose new methods and ways to approach teaching-learning process. The concern around all these figures brought Adela Acitores and Silvia Nuere to present an innovative project in their university. They wanted students think about the problem of the indiscriminate use of plastics and propose a way of raising awareness on this issue.

\section{Method}

Looking at some data from the problem of plastics as waste impossible to recycle, some professors wanted to tackle this matter making students 
be conscious. Universities can become laboratories of awareness through problem-based projects.

Even though our proposal is set in Spain, it can be extrapolated to other spaces and other countries. The innovative learning project aims at focusing on the big problem that plastic waste is causing to the environment and the necessity of acting against it. Our university, and universities in general, are good boosters to reflect on this matter, from our students but also from our teachers.

Learning methods must adapt to the European Higher Education Area (EHEA), developing a range of skills on the students. Once students leave university, they will face new challenges in a professional career. There is a need to change from the traditional way of teaching to a more active participation of the students.

In a hectic and modern world, we need to adapt teaching and learning to new ways of proceeding, concerning theory, practice, planning, thought, and action. We think that it is necessary training based on a more global and comprehensive perspective, in which enhance interdisciplinary, social, and cultural competences. In the XXI century we look for new teaching-learning method according to the knowledge to be transmitted (Tippelt \& Lindemann, 2001).

Teaching based on competencies is one of the most recent movements in higher education. Professional competencies applied into the universities required designing a model where students must tackle a problem providing solutions where they can implement their knowledge. Proposed projects can be developed in laboratories or workshops or be framed in real contexts ( Brunel \& Viesca, 2014).

Nowadays, between the different possible methods, the Projected Oriented Learning (POL) is a variant of the Project Based Learning (PBL) in which the professor raises a project to a group of students. This methodology favors students to become more active, responsible, and committed to their learning (Morales Vallejo, 2008).

As students work in groups, these learning models, according to De Miguel (2005), stimulate the following abilities, between others. We highlight the most suitable for the project with a brief description they can specifically follow:

Planification and organization: as they are different students and have a limited time to develop the project, they need to distribute needed tasks.

Analysis: what is the specific statement of the proposal (the indiscriminate use of plastics) and how they are going to face this problem and transmit it.

Synthesis: topic and design proposal according to their field of knowledge. 
Investigation: research about plastics characteristics, possible realization, and means they will need.

Transfer of knowledge and extrapolation to other contexts: even though every group belongs to a specific degree or master's, they may be permeable to other disciplines.

Critical thinking: it is not a simple matter of making a product, but a way to raise awareness about the problem, and think about.

Individual and group responsibilities: every single person must acquire a responsibility into the group.

Management of different disciplines and sources of information: research, product, idea must meet the principal objective.

Oral and written expression: they must present their proposal to the mates, and professors.

Teamwork: working together benefits the result.

Leadership: this leadership can be understood as not individual but comparing to other groups.

Decision making: every problem needs a solution, and they must be conscious that soon they will have this responsibility.

Tackle these abilities in the university field will favour students to face in a better way their professional career. It is about simulating similar conditions by proposing a project based on the reuse of plastic nets from the packaging of fruits and vegetables.

\section{Innovative learning project proposal}

'Network Design' is an interuniversity, interdepartmental, interdisciplinary, and collaborative project. It is a collective effort, from the academy, to reflect on the huge amount of plastic waste that in the long term is harmful to the environment. Products initially and sometimes are necessary, but perhaps replaceable.

'Network design' is based on plastic nets made for carrying fruits and vegetables. Fortunately, they end up in the plastic garbage. At worst, trapped in the marine vegetation or martyring the fish in our oceans.

What if those nets, which are harmful because of the abusive and disproportionate use we carry out, can also be beautiful in their end? What if the designer, the dreamer, the innovator, the creator, imagines another end for them? What if we, as a claim to good sense, could restore their dignity and give meaning to their lives?

'Network design' seeks, in a poetic key, to raise the issue of recycling and looks for a different use of plastics. It is not an investigation to generate peace of mind thinking about reducing the percentage of garbage. It is a cry, a complaint that aims to sensitize all sectors to understand the importance of the useful life of products and their packaging. It raises the 
need to foresee the future of the accumulation of waste advocating a conscientious, knowledgeable, and supportive consumption in the future.

'Network design' wants to address, from different fields of creation and design, and from university classrooms, a different vision of those heaps of "useless" nets that are only useful until they reach our homes but that will exist for years. It is up to us to dignify production by giving dignity to products and studying the consequences that waste generates.

The project has started in the academic year 2019-2020 but due to the COVID-19 pandemic, was extended until the end of the course 2020-2021.

\section{Results}

Professors from the different universities launched the project. To understand each proposal, we will present the statements of the proposal according to each subject.

1. IADE School of Design, in the master's in design and fashion, and luxury management, and the subject Materials and textile design; materials and innovation (experimental pattern), which professor is Brezo Alcoceba.

The concept of the proposal was: Development of a Zero Waste Do it Yourself (DIY) garment reusing fruit and vegetable nets. The fruit and vegetable nets were reused, thus demonstrating the potential of their utility beyond use and throw away.
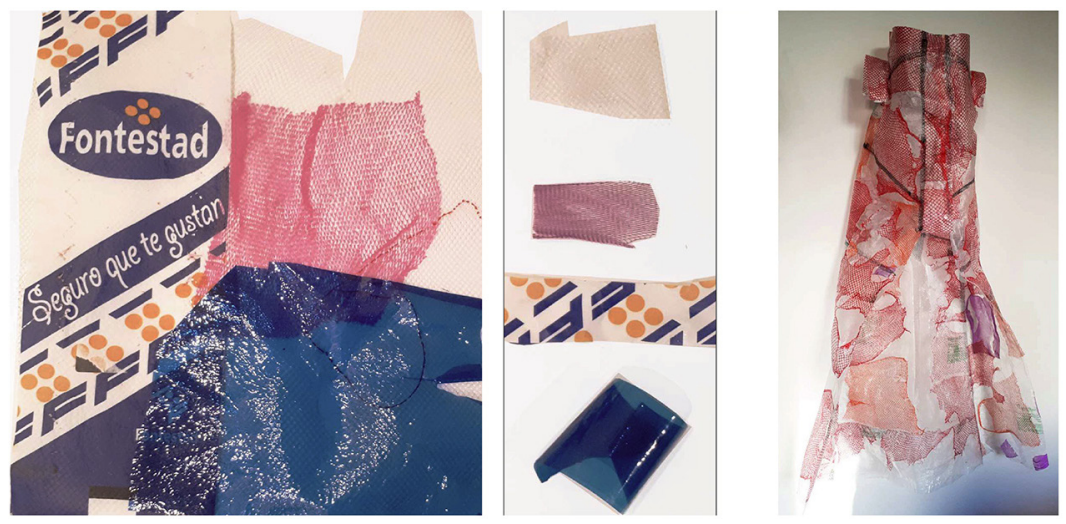

Figure 1. Dress patron. Sira H. Cortés

2. URJC, in the subject Complement design in the Degree of Fashion Design and Management (URJC), 3rd year, which professor is Brezo Alcoceba.

The main objective of the project was to develop clothing proposals made with innovative materials based on the recycling of fruit and vegetable nets. To achieve this main objective, an exercise was proposed within 
the framework of the Complements Design subject in collaboration with Jewelry Design: the prototyping of a one-piece-construction bag.

Why a bag? The bag is the quintessential fashion accessory. Its interest as a small-format three-dimensional entity that allows us great versatility when it comes to studying its shape, material, function, texture, and size. Why one-piece-construction? Compared to the traditional construction by pieces, the generation of a three-dimensional volume is investigated from the treatment of a single two-dimensional surface. In this way, the interest of material innovation is prioritized over the complexity of the pattern.

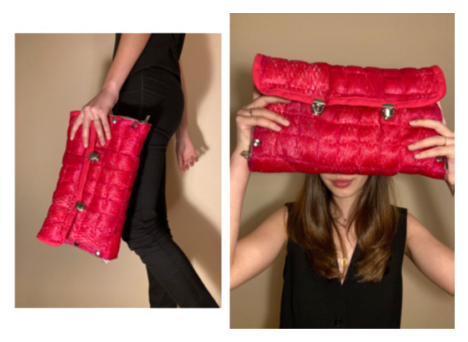

Figure 2. Bag design. Marta Carrascal González, Olga de la Oliva Domínguez Ligero and Juan Manuel Ferrufino Rojas

\section{ESQUEMA DE REDES Y MATERIALES FINALES}
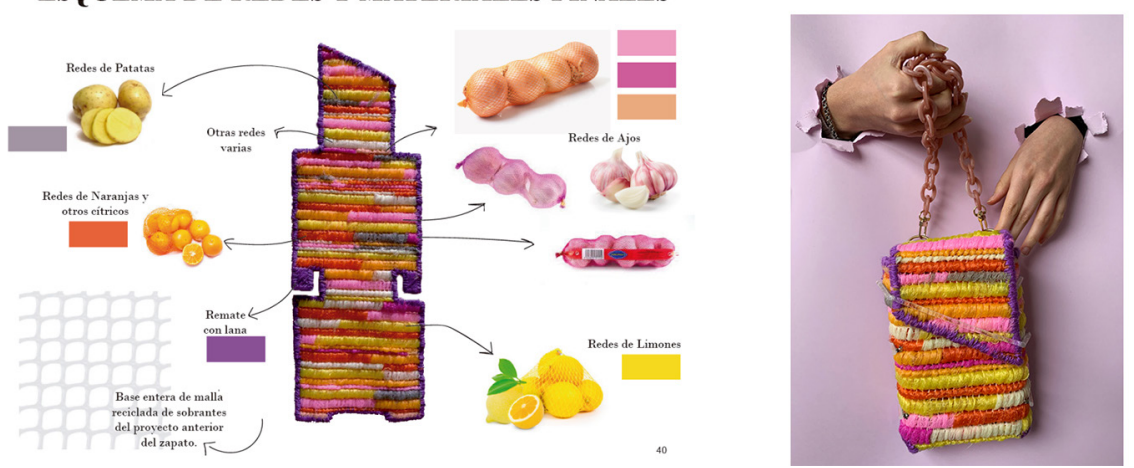

Figure 3. Bag design. Marta Corrochano Oliva, Sara Labraca Cerón and Natalia Las Heras Rodríguez

3. Universidad Complutense de Madrid (UCM), in the Degree of Fine Arts, and the subject Landscape Painting, in the 4th year, which professor is Esperanza Macarena Ruiz Gómez.

From the Landscape Painting subject, within the teaching syllabus of this subject, the topic dedicated to collage is selected to participate in this project with students, considering it ideal to introduce the net as an integral element of the students' work. 
Collage is an artistic technique that essentially consists of gluing or combining elements of various materials, colors, and textures on a support. This technique is also very useful in artistic training, since it will let students developing their spatial arrangement, as well as their ability to geometrize. In this proposal nets that serve to wrap fruits and vegetables give free rein to the use of different textures, with their different colors and thicknesses. They must introduce them in a compulsory way in their work. Following it, they encourage a second life to this material.

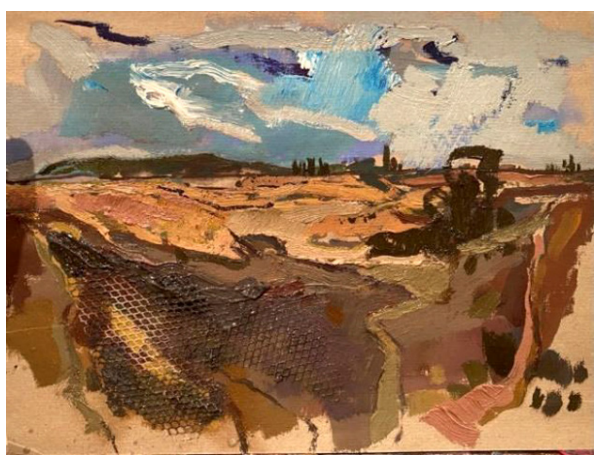

Figure 4. Landscape. Oil and net on paper. $22 \times 28 \mathrm{~cm}$. Macarena Ruiz Gómez.

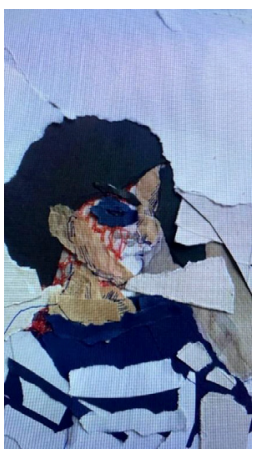

Figure 5. Artistic collage. Teresa Vicente Illoro

Due to the COVID-19 pandemic, some of the proposals are not landscape paintings as student could not go out for painting or only had building views. Portrait was one of the other options (Figure 5). This confinement situation also influenced the format of the works since most were carried out in the students' field notebooks.

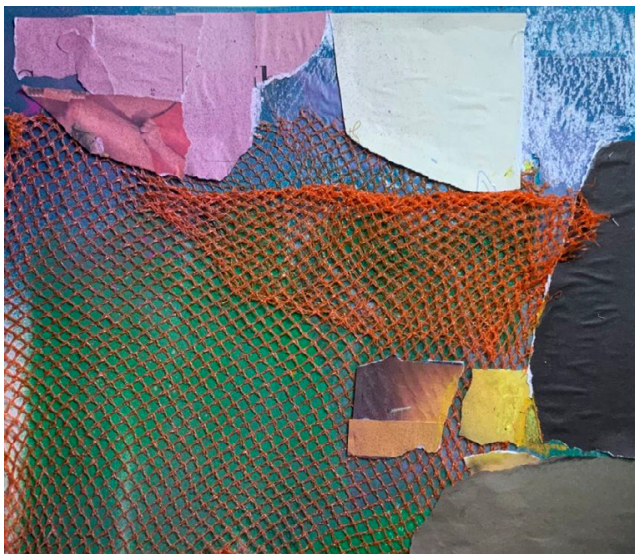

Figure 6. Artistic collage. Irene Anguita Cuadra 
4. Universidad Politécnica de Madrid (ETSIDI-UPM), in the Degree in Engineering in Industrial Design and Product Development, and the subject Basic Design, in the $2^{\text {nd }}$ year, which professors are Adela Acitores Suz and Silvia Nuere.

After collecting as many nets as possible, different sizes, characteristics and colors, the students are asked to reflect and analyze the qualities they present to move on to an experimentation phase. Nets can be sewn, glued with heat, added to other structure to make them more reliable in the function they are intended to fulfill.

The members of the group will describe the characteristics and possibilities of the application of the material. Tools such as "mind maps" or "brainstorming" can be used.

Among the four members of the group, four design ideas should come out. They need to evaluate them based on the suitability of the material for the practical function, the formal solution given or the good design of the applied solution. Other materials can be used in a complementary way, although the design must be based on material produced from plastic nets.
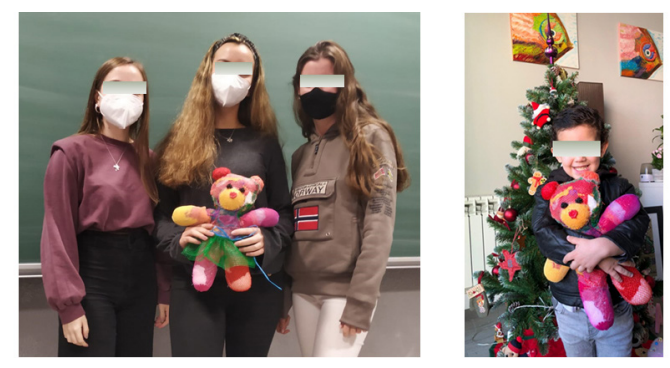

Figure 7. Teddy Bear. Marta García-Moreno Brazal, María Martín Prado, Alejandra Fernández Gil, Estíbaliz Cabrera García

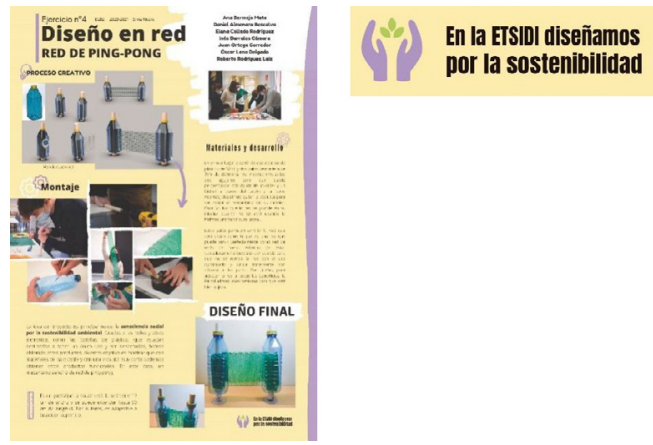

Figure 8. Design of a net for Ping Pong game. Bermejo, A., Almenara, D., Collado, E., Barrales, I., Ortega, J., Lana, O. \& Rodríguez, R.

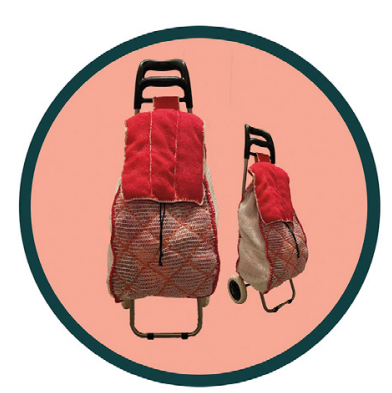

Figure 9. Net Cart. Molina, A., Pariente, E., Sagredo, C, Pulido, C. \& Tormo, p. 
As seen in an example, all students presented a panel with the most significant characteristics of their product as well as the process carried out.

5. Universidad Politécnica de Madrid (ETSAM-UPM), in the subject Decorative Trends and Styles-III, which belongs to the course of End of Degree Project of the Degree in Interior Design, which professor is Manuel Carmona.

This work appeals to recycling, to the application of technique, ingenuity, sustainability, environmental protection, aesthetics, and poetics. The results reflect the purpose of reusing and taking advantage of nets, for domestic use, which contain the fruits and vegetables of our daily consumption, for application to Interior Design.

Within this context, the main objective of this work has been to devise and make prototypes that eventually become products that can be applied to Decorative Arts. As a big scale, or from a very close view, nets appear to be different and to suggest different proposals. This is the reason why some of the proposals reproduce forms of nature: flowers, sea waves, jellyfish, etc. The chromatic variety has also been highly appreciated in every project.

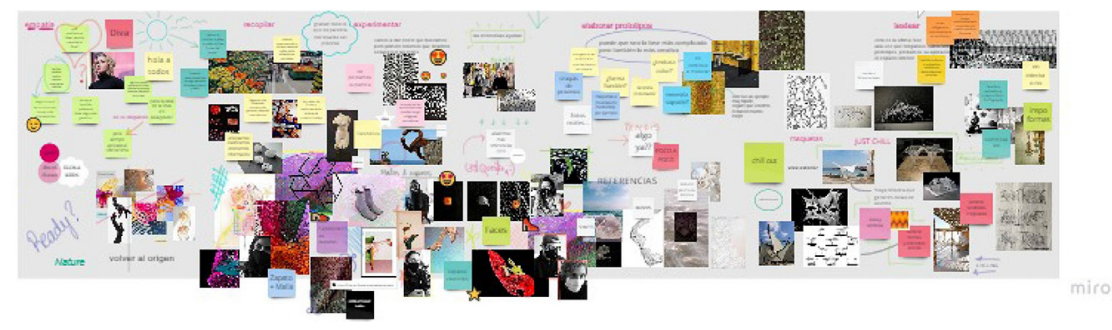

Figure 10. Common working panel. Materials Workshop Web Design. Interior Design UPM

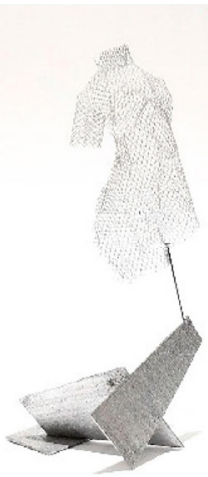

Figure 11. Prototype: mesh sculpture. C. Morales, E. Gruber, A. Vivanco, L. Buño, B. de Miguel
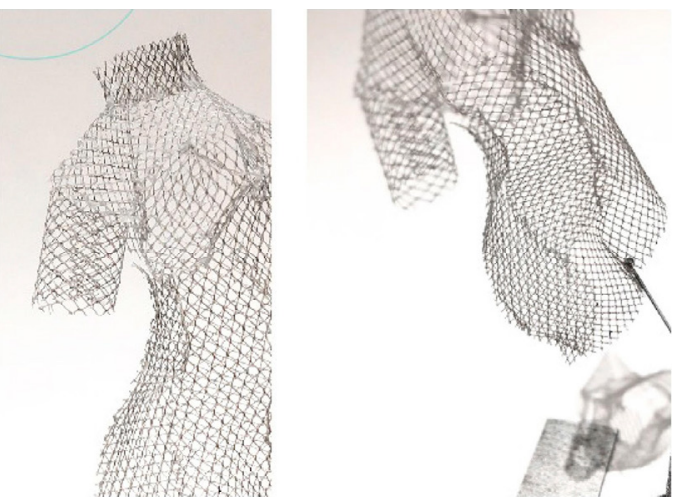
6. ETSIDI- UPM in the subject Artistic Drawing of the Degree in Engineering in Industrial Design and Product Development, which professor is Silvia Nuere.

The application of the nets went carried out in the section of the conical perspective.

Alberti described for the first the conic perspective in his book "Della Pintura" in 1436, defining the paint plane, the point from where to draw, perpendicular lines, horizontal line, and other elements. He compared it with a window and established that it was the best way of representing with method (Dubery \& Willats, 1983, p. 56). Using a "Leonardo Window" made by the teacher, they had to draw in an acetate sheet a view chosen by them and use plastic nets to face an artistic proposal.

A line drawing was made with an indelible marker, with Leonardo's Window, on an acetate sheet. Then, by studying the nets, their characteristics, weft, color, and possible combinations, these were artistically integrated into the acetate, in the way they consider best.

Being an artistic proposal, the options are endless and what is sought is the expressiveness of both the conical perspective layout and the incorporation of color and textures that nets allow us. Nets can become means for expressing yourself.

A small reflection on the indiscriminate use of the nets and how the proposal can contribute to raising people's awareness is needed.

In the examples we can see pictures taken during the process drawing with the "Leonardo Window" and final work.
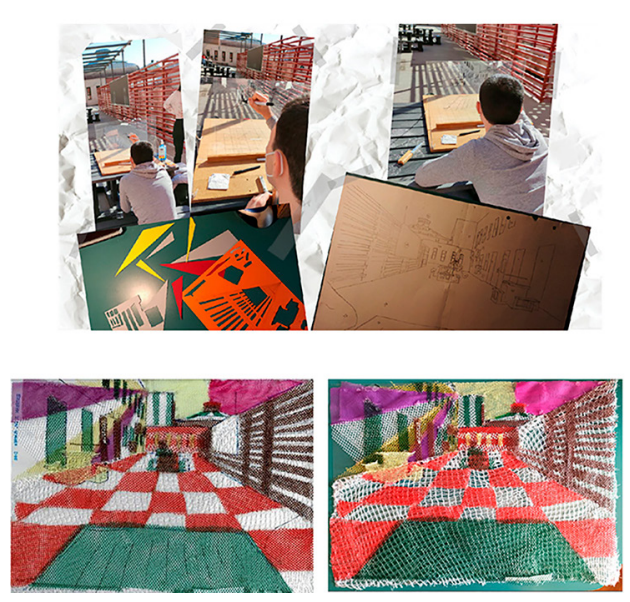

Figure 12. "Leonardo's Window" perspective proposal. Esteban Gil.

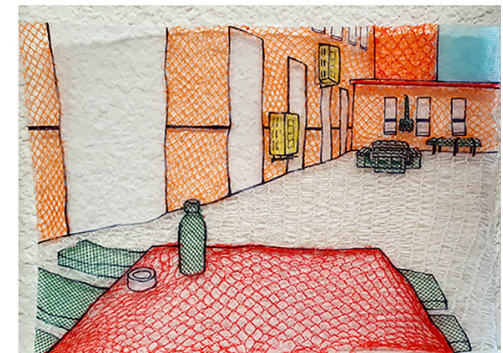

Figure 13. "Leonardo's Window" perspective proposal. Nicola Kowalczyk 
7. ETSIDI-UPM in the subject Visual Communication of the master's degree in Engineering in Industrial Design, which professors are Raúl Díaz-Obregón and Silvia Nuere.

The main objective is the proposal of a message where nets play a fundamental role as a claim to raise awareness about the indiscriminate use of plastics. The idea must come with a materialized product. They need to create something and later think about the best message that could match their ideas.

Next, an explanatory panel will be held where all the elements of visual language, as composition, and visual rhetoric will be studied to compose a coherent message. Nets can be applied in any way where colors, textures, shapes, and the adaptation of the meshes make up the essence of the message. A document will include the process carried out, the evolution of ideas and the justification of the final proposal of the group.

The options are endless and what you are looking for is an attractive, powerful message that hooks the viewer's gaze and makes them reflect on the indiscriminate use of nets and how the proposal could contribute to raising awareness for responsible use.

Figure 14. Pasaguas. Marta Contreras, Marta del Val, Óscar Gil \& Alejandro Vélez

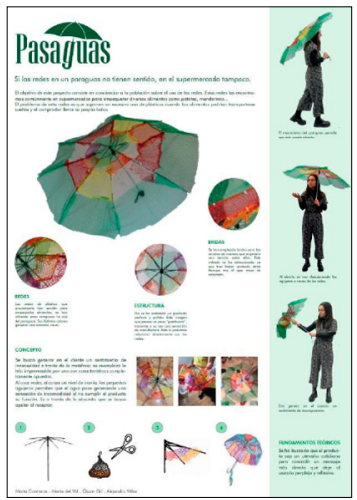

In this proposal there is a play-on-words with the name "umbrella" in Spanish ("Paraguas"). Its translation is "stop water" and the new name is "Pasaguas" which translation is "Pass Water".

Figure 15. Poster imitating the face of Frida Kahlo with flowers made of plastic nets, in the head. Manex Garay Beristain, Angeliki Karapiperi Stamatakopoulou, Borja Mata Sebastián \& Carmen Ruiz de la Bastida

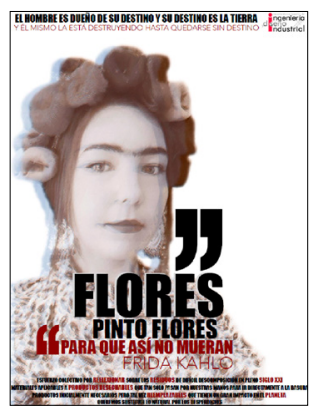


8. UNIR in the subject Fundamentals of creativity workshop of the Degree in Digital Design, which professor is Laura de Miguel Álvarez.

The objective is to enhance the educational possibilities offered by waste material when used as the protagonist of a visual discourse. It also intends to use the communicative power of the fixed image to build a visual narrative loaded with meaning. The narrative is built from an argument, a beginning, and an ending and what happens in that timeline.

Storytelling is a tool for creativity and imagination and gives us the opportunity to build on the new, trying the diverse to engage in understanding and visualizing it. Normally we find the narrative through images in the audiovisual universe, but it is also possible through a single image. It is about exposing a narrative in such a way that the viewer is caught immediately.

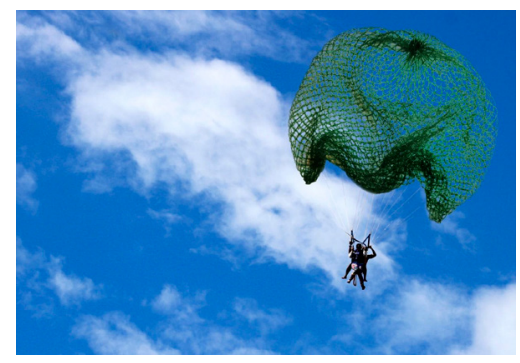

Figure 16. Jonathan Piqueras

\section{Professional collaboration}

Even though this was an innovative project focus on students, we also spread the idea to some professionals. The project will end in November 2021, but in May 2021 we had already received the proposal of a well know Spanish photographer. His name is Jordi Valls Capell. He likes to photograph something else than an instant. He wants to show a piece of a universe in constant movement.

He has photographed some flowers and has made another one inspired in the first one but made with plastic nets (Figure 17). It is a poetic approach to raise awareness about the indiscriminate use of plastic.
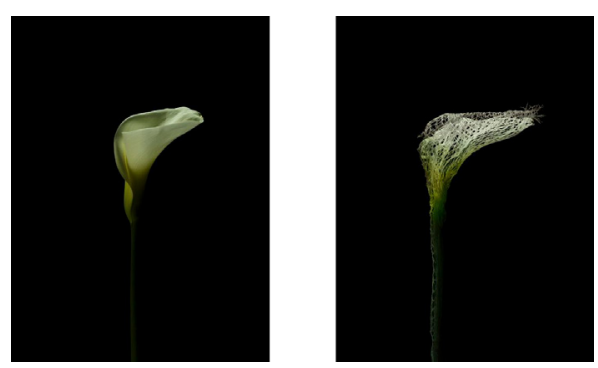

Figure 17. Flowers. Jordi Valls Capell 


\section{Discussion}

We want to highlight the main achievements of the students' proposals.

\section{IADE School}

Throughout the process they have experimented with the possibilities of plastic nets, creating a catalog of thermo-fixed textures to investigate their behavior against heat and a catalog of handmade textures.

The process offered a reproducible garment through DIY instructions (Figure 1) that will be uploaded to the Instructables platform so that anyone, anywhere in the world, can bring it to life again and take it further with a Creative Commons license and following instructions can make their own piece.

\section{URJC}

The wide range of results is very remarkable. Regarding design, highly recognizable typologies such as the baguette or the clutch have been generated, as well as others (Figure $2 \& 3$ ). In all of them a very diverse color palette is achieved, from the most defined tones (segregated net) to the most indeterminate (overlapping nets). Regarding its elaboration, the applied techniques are very diverse: textile art strategies such as quilting, embroidery or crochet are reinvented to adapt them to the treatment of this specific material, and some more alternatives such as thermofusion are generated.

\section{UCM}

Being an interdisciplinary project and considering that one of the main objectives is taking care of the environment, the discipline of Landscape Painting is ideal to participate (Figure $4 \& 5$ ). Although the dominant one is the pictorial practice, it is carried out from dialogue and direct contact with nature, taking it as a model and respecting it as a source of inspiration.

As can be seen in the results obtained, the amount of this material used in the works is in some cases symbolic, thus not avoiding the continuous message of contamination of our natural landscape (Figure 6). The presence of this material 'the nets' in the students' collages, have been used mainly as a claim and awareness to promote recycling in the classroom as well as caring for the environment.

\section{ETSIDI - UPM}

\section{Basic Design}

The options presented by the Basic Design students were varied but in all of them a product made using the fruit and vegetable nets was delivered. Most of the proposals were made in a life-size scale.

Considering that these students are in a degree in engineering in industrial design, they also had to carry out a study on the characteristics of the material (nets) to understand that, based on the properties they could make 
one design or another. You can find differences between a proposal where the object needs to be exposed to certain forces, and a bear like a cuddly toy (Figure 7).

To sum up there were a variety of proposals, covering various uses, with real and functional prototypes where nets were the protagonists with varied colors and textures.

In a case, the proposal went beyond the materialization of a product (net for Ping Pong game), designing a logo for the School they belong ("In the ETSIDI we design for sustainability") (Figure 8). The idea is to make every one of the community aware of the need to embark on a path towards sustainability in all actions carried out at the university.

The group that made the net cart went shopping with it and checked its resistance and capacity (Figure 9). In this case, they recycled the structure of another one damaged and gave it a second life.

\section{Artistic Drawing}

Combining the necessary skills for a good drawing and considering the present problem of excessive use of plastics, the proposal for these students was the combination of conic perspective with an artistic approach (Figure $12 \& 13)$. They have chosen nets of striking colors and for others some that are more in line with the color of the real element.

This activity has made them see how impractical plastic nets are, as one student points out in their work. Basically, they are produced to be simple to use and to be thrown away practically instants after fulfilling their function.

\section{Visual Communication}

In the subject Visual Communication of the master's in Engineering in Industrial Design, students face the knowledge of the elements that make possible a good understanding of an image. The decisions taken about a combination of shape, texture, light, color, composition, and visual rhetoric can drive them to a specific message. The excessive use of plastics is a perfect topic to deal with searching for a strong message that could make people think about (Figure 14).

All proposals are related to the idea of the plastics uselessness comparing them to the product they made; for example, an umbrella made of plastic nets or a swimsuit completely transparent.

In another proposal, students made a poster. In the picture a student appears as if she was Frida Kahlo, with a quotation from her (Figure 15). The flowers of her head are made of plastic nets. The text that appears at the bottom says:

"Collective effort to reflect on residues of difficult decomposition in the XXI century. Materials applicable to disposable products that only pass through our hands to go directly to the trash. Initially necessary but 
perhaps replaceable products that have a huge impact on the planet. We want to substitute the natural for the waste."

\section{ETSAM - UPM}

The process was also about experimenting, collecting, and obtaining sufficient material for its dissemination, as well as documenting the entire development through sketches, images, videos, etc. It is about talking about materials and the options they allow to work on (Figures 10 \& 11).

After its completion and seeing the results, it can be said that, after a first sharing, the sinuous forms of the nets have seduced the students.

\section{UNIR}

Students have used plastic nets to catch the attention of the viewer. They worked with the combination of plastic nets, photos or arranging a scene to create the narration.

With the use of waste material, they have known how to value its artistic potential and the possibilities offered by the networks as protagonists of a visual discourse (Figure 16).

To sum up and as a general comment, it is empirically corroborated that the food net, a material born with an expiration date due to its use as temporary packaging, can have a second life of a permanent nature. Its appeal is not only functional, but also highly visually attractive when applied in the field of accessories and being extrapolated to any other field of fashion, art or design.

Thanks to the exercise, students have reflected on ways of being able to reuse the nets promoting the creative possibilities offered by them, becoming protagonists. The nets are born from the head simulating the imagination, full of light, and all kinds of thoughts, which ultimately try to reflect that creativity can never be imprisoned.

Maybe the logo is one of the clear examples of reflection beyond the materialization of products as well as the posters made by the students of the subject "Visual Communication". The message about be conscious about the indiscriminate use of plastics is perfectly state. In the other cases, the final goal will be better exposed in the exhibition that will be held in October 2021, where people will see the effort made by students and teachers at a glance. Some conferences are planned to publicize the scope of the project and possibly this sharing is what distinguishes our project from others, a multidisciplinary work with a single objective.

\section{Conclusions}

Engineering students in industrial design had to analyse the material, its behaviour, and the most appropriate processes to later apply to the chosen idea. In the case of Fine Arts students or in the subject of Artistic Drawing, 
nets became textures that accompany students' expression. For the Master of Fashion students, the nets formed the fabrics that would form a dress as an experimental pattern. Plastic nets served as perfect materials to make bags, decoration elements or stories to tell about a specific message. Different media were used to communicate their proposals. Plastic nets become a perfect element to tell a message through a rhetoric figure. Analysing form, texture and colour, nets become decorating elements. Different proposals for a unique purpose: raise awareness about the indiscriminate use of nets that are thrown away.

They are also easy to melt so that they can be reconverted with other shapes and even mixed with other plastics that give them greater resistance, thus expanding their range of applications.

It is important to highlight the above: in the creative aspect, the original qualities of the nets have been considered. By maintaining the original colours and textures, the processes and results obtained are very much in favour of sustainability. The proposals are respectful with the environment. The production processes seem simple and do not require complicated infrastructures to carry them out.

At the same time, work has been done on poetics. The solutions given are very attractive, but they are also feasible. This makes them doubly beautiful. It is also important to point that even though students had to make the proposal, all relatives, friends, and mates were involved in collecting nets. It is a work of months and months, also seeking the most suitable one for their product.

From the university we think that these generations of students should be formed from an early age in this global consciousness and that thanks to activities of this nature they experience and better assimilate the message. They will also be able to transmit it, and when they reach professional life, they may remember these activities and be able to start projects of a larger nature.

After the development of the different workshops and the results obtained, it should be said that through recycling and the use of fruit and vegetable nets there can really be multiple possibilities to generate elements of interest within different fields.

Nowadays, more than reflections, these words should be made given that the uncontrolled rhythm that we have of production and consumption, as the experts already reflect, do not bring much happiness.

We should try to meet two objectives: that they do not end up abandoned anywhere, since they can contaminate and damage fauna, and try to stop production (either from nets or some other product) by looking for other more ecological materials, creating a cycle with those that already exist so that they are needed anymore. 
Multidisciplinary nature is essential so students can see in each other ways of reacting, work and think. They have also seen proposals from the first course of a degree, going through all the courses until the fourth, and in the master's in engineering in industrial design.

There are infinite ideas between those discovered and those yet to be discovered. Thus, in addition to the presented proposals, we also invite people to develop their creativity so that they win in all aspects.

Even though the main objective was the awareness of the incredible number of plastics we use, the products they have designed and made have a very good quality and therefore, exhibition will be held in October 2021 with the main objective, as already mentioned, to show the project done from different fields of knowledge.

\section{Acknowledgments}

We want to thank all the people that have participated in this innovation project with their enthusiasm and commitment.

\section{References}

De Miguel Díaz, M. (2006). Metodologías de enseñanza y aprendizaje para el desarrollo de competencias. Orientaciones para el profesorado universitario ante el Espacio Europeo de Educación Superior [Teaching and learning methodologies for the development of competencies. Guidelines for university teaching staff before the European igher Education Area]. Madrid: Alianza Editorial.

Dubery, D. \& Willats, J. (1983). Perspective and Other Drawing Systems. Van Nostrand Reinhold Company: New York.

European Comission. (2020). Nuevo Plan de Acción para la Economía Circular [New Action Plan for the Circular Economy]. European Comission in Spain. Retrieved from: https:// ec.europa.eu/spain/sites/default/files/20200311_circular-economy-plan_es.pdf

Greenpeace. (s.f.). Datos sobre la producción de plásticos [Data on plastics production]. Retrieved March, 2021, from: https://es.greenpeace.org/es/trabajamos-en/consumismo/ plasticos/datos-sobre-la-produccion-de-plasticos/

Herrerías Brunel, C., \& Isoard Viesca, M. (2014). Aprendizaje en proyectos situados: la universidad fuera del aula. Reflexiones a partir de la experiencia [Learning in situated projects: the university outside the classroom. Reflections from experience]. Sinéctica. Revista Electrónica de Educación (43), 1-16. Retrieved from: http://www.sinectica.iteso. $\mathrm{mx} /$ articulo/?id $=43$ _aprendizaje_en_proyectos_

International Union for Conservation of Nature. (May, 2018). Marine Plastics. Gland, Switzerland: IUCN. Retrieved from: https://www.iucn.org/resources/issues-briefs/ marine-plastics

Mascareñas, p. (s/f). [Actúa] consejos para una vida sostenible [Take action. Tips for a sustainable life]. Greenpeace. Retrieved from: http://archivo-es.greenpeace.org

Morales Vallejo, p. (2008). Nuevos roles de profesores y alumnos, nuevas formas de enseñar y de aprender [New roles for teachers and students, new ways of teaching 
and learning]. In L. Prieto Navarro, La enseñanza universitaria centrada en el aprendizaje [University teaching focused on learning] (pp. 17-29). Barcelona: Octaedro.

Persson, O. (2015). What Is Circular Economy? Uppsala, Sweden: Uppsala Universitet. Retrieved from: https://www.diva-portal.org/smash/get/diva2:841910/FULLTEXT01.pdf.

Plastics Europe. (2019). Plásticos - Situación en 2019 [Plastics - Situation in 2019]. Retrieved March 14, 2021, from: file:///C:/Users/SN/AppData/Local/Temp/Plastics_ the_facts-Mar2019-esp.pdf

Tippelt, R., \& Lindemann, H. J. (2001). El método de proyectos [The projects method]. El Salvador/Berlín: Ministerio de Educación de El Salvador/Proyecto APREMAT. Retrieved from: http://www.halinco.de/html/doces/Met-proy-APREMAT092001.pdf 